\title{
Determination of the number of Vertical Axis Wind Turbine blades based on power spectrum
}

\author{
Waldemar Fedak ${ }^{1}$, Stanisław Anweiler ${ }^{1, *}$, Wojciech Gancarski ${ }^{1}$, and Roman Ulbrich $^{1}$ \\ ${ }^{1}$ Opole University of Technology, Department of Mechanical Engineering, 5 Mikołajczyka st., 45-758 Opole, Poland
}

\begin{abstract}
Technology of wind exploitation has been applied widely all over the world and has already reached the level in which manufacturers want to maximize the yield with the minimum investment outlays. The main objective of this paper is the determination of the optimal number of blades in the Cup-Bladed Vertical Axis Wind Turbine. Optimizing the size of the Vertical Axis Wind Turbine allows the reduction of costs. The maximum power of the rotor is selected as the performance target. The optimum number of Vertical Axis Wind Turbine blades evaluation is based on analysis of a single blade simulation and its superposition for the whole rotor. The simulation of working blade was done in MatLab environment. Power spectrum graphs were prepared and compared throughout superposition of individual blades in the Vertical Axis Wind Turbine rotor. The major result of this research is the Vertical Axis Wind Turbine power characteristic. On the basis of the analysis of the power spectra, optimum number of the blades was specified for the analysed rotor. Power spectrum analysis of wind turbine enabled the specification of the optimal number of blades, and can be used regarding investment outlays and power output of the Vertical Axis Wind Turbine.
\end{abstract}

\section{Introduction}

European Union directives, as well as increasing environmental awareness, together with decreasing energy resources of the planet, are forcing us to look for non-conventional and renewable energy sources at the same time. As of today, the use of these resources for economic reasons is less profitable than obtaining energy from fossil fuels, so renewables must be subsidized or protected by the government [1]. However, this does not remove the search for more efficient solutions. Economic growth, energy demand, energy security and sustainable development require application of renewable energy sources, especially in urban areas [2].

Wind energy has become an important source of electricity production due to its abundance in nature and low environmental pollution. Advanced techniques have been developed to achieve as much energy as possible with the energy conversion equipment - wind turbines [3]. At present, there are two main fields of harvesting wind energy. High altitude and low altitude winds exploitation. Although high altitude winds are considered to be the most promising renewable energy source in the future [4], low altitude wind technologies are well settled and developed. There are two categories of modern low altitude wind turbines, namely horizontal axis wind turbines (HAWT) and vertical axis wind turbines (VAWT), which are used mainly for electricity generation and pumping water. The main advantage of VAWT is a single moving part (the rotor) where no yaw mechanisms are required, thus simplifying the design configurations significantly [5].

VAWT can be divided according to the way of wind energy conversion to the rotor.

1) Active VAWT - the use of aerodynamic effect (lift) Darrieus and H-rotors.

2) Reactive VAWT - the use of thrusting force (drag) Savonius and differently called cup /bucket /drum /carousel /scoop bladed-rotors.

Recently a hybrid approach to VAWT is becoming more noticeable [6], where active rotors are combined with reactive ones. Smaller, reactive VAWT are mounted on the larger active VAWT's shaft. Reactive VAWT is used as starter for the active VAWT. Hybrid approach to electrical generation is also observed in developing hybrid renewable energy plants with solar and wind power [7]. Sustainable development requires also high economic performance analysis of the renewable investments (for instance with the use of discounted method [8]), so comparison between HAWT and VAWT economic performance is also available [9].

In general, the electrical generation industry is currently in a period of considerable flux caused by (i) obsoletion of central generation, (ii) a desire to decarbonise network generation and (iii) a need to diversify fuel sources to enhance energy security. The effect of these drivers will clearly effect change in network scale infrastructure but they may also offer an opportunity for distributed power generation. There is a growing body of opinion that policy should be developed

\footnotetext{
Corresponding author: s.anweiler@po.opole.pl
} 
to promote the widespread adoption of highly distributed, micro-scale generation in the built environment in general and in the domestic sector in particular. This form of distributed generation is widely seen as a beneficial development in terms of both energy security and decarbonisation of the delivery of electricity to the built environment. Governments are seeking to enshrine the adoption of micro generation technologies through the building regulations, setting a target for net zero carbon new build housing. Micro wind is one of the technologies represented in this sector that could develop into a market-mature technology applicable for widespread adoption. Previously the majority of micro wind turbines were installed for educational reasons (at schools or environment centres) and very few domestic systems existed, especially in urban areas. Installations were dominated by Horizontal Axis Wind Turbines in the $2.5-20 \mathrm{~kW}$ range. However more recently the small wind turbine industry has started to focus on developing the smaller $(<1.5 \mathrm{~kW})$ building integrated turbine market. In particular there has been a push to develop rooftop installations that are suitable for domestic properties in the urban environment. These technologies are generating positive interest from both public and private sectors, with their availability extending to Do It Yourself stores [10]. The type of turbine to be used in a particular project depends mostly on the local circumstances, such as housing density, altitude and the wind velocity, direction and their variability. In the area of high building density there is most demand for electricity but also it is extremely difficult to determine the wind direction. On the basis of authors observations it seems that the cup-bladed rotors are the least affected by the direction of wind vector. That is why the authors took a closer look to reactive VAWT with the use of thrusting force cup-bladed carousel. Although these types of VAWT are known for long time, there is not much research put on gathering high quality experimental data [11]. There are some trials but in a very simple manner [12]. Literature analysis reveals the gap in the research field of the reactive vertical axis wind turbines, especially for cup bladed rotors and their mathematical models. This is the motivation and background of the authors research.

\section{Basic problem}

The main problem in the design and maximization the performance of a wind turbine, beside the shape and size of the rotor and the blades, is to determine the number of the blades mounted on the rotor. Each cupbladed VAWT has specific, optimal number of blades, depending on various factors, such as size and materials used. Number of blades can vary, the bigger amount of the blades, the more they will obstruct one another during operation - slipstream. This will reduce the performance of VAWT. For the analysis, a set of blades in the shape of a hollow semi-cylinder, completed with semi-circular domes have been used. The study involved a series of rotors fitted with 2 to 7 blades. Fig. 1 presents the blade and sample rotor consisting of 5 blades.
VAWT with only 2 blades will not work at all, but it is taken into account as a reference.

Detailed literature review shows lack of experimental data according drag force research in the field of drag turbines, especially physical measurements of forces on the blades. All gathered data refer to numerical research for Savonius type rotors. The carousel type rotors are not represented in the literature. To start mechanical tests one must first make some theoretical assumptions and verify them. These assumptions are the main problem and the purpose of the research.

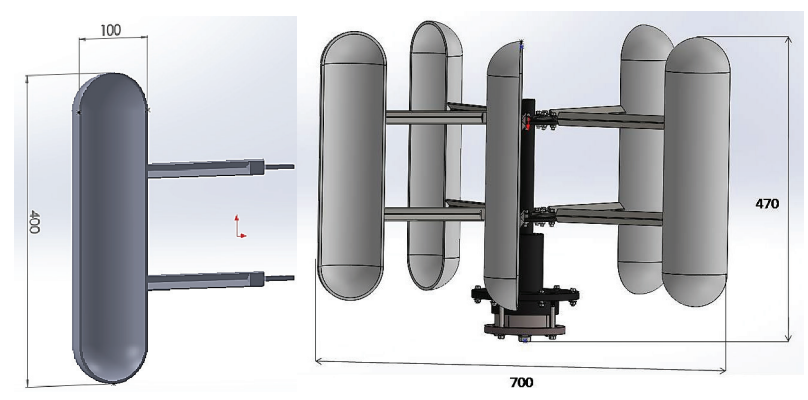

Fig. 1. CAD model of the cup-blade and the 5-bladed carousel rotor.

\section{Methods}

Cup-bladed carousel turbine is operating on the same principle as the Savonius turbine and is one of the simplest wind turbines. Aerodynamically, it is a dragtype device, consisting of certain number of airfoils blades scoops. Because of the curvature, the blades experience less drag when moving against the wind than when moving with the wind. The differential drag causes the turbine to spin. Because they are drag-type devices, these turbines extract much less of the wind's power than other similarly-sized lift-type turbines. Cup-bladed VAWT rotor rotates under the torque difference caused by different resistance (drag) that make the concave and the convex side of the blade. In order to make theoretical calculations certain rules and simplifications have been set. Due to the fact that the movement of air masses is not homogeneous and is usually turbulent, it was decided to perform the initial calculations for laminar flow. The simplified calculation, when considering the impact of the air stream on the blade does not take into account what is happening around the blades. Only impact of the air stream on the cup-blade. For the computing purposes the width of the air stream is comparable to the width of the blade. The blade movement speed is zero. Another assumption is that the energy of the wind stream is completely transformed into kinetic energy of the blade [13]. Schematic view of the hydrodynamic thrust on the obstacle from the concave face is shown in Fig. 2.

To calculate the thrust of the rotary turbine blade on a single concave side facing the thrust, as shown in Fig. 2, equation (1) was used, characterized by the hydrodynamic pressure [13]. Formerly used for Savonius rotor [14], next for straight blade [12].

$$
P=A \cdot \rho \cdot v^{3} \cdot(1+\cos \delta)
$$




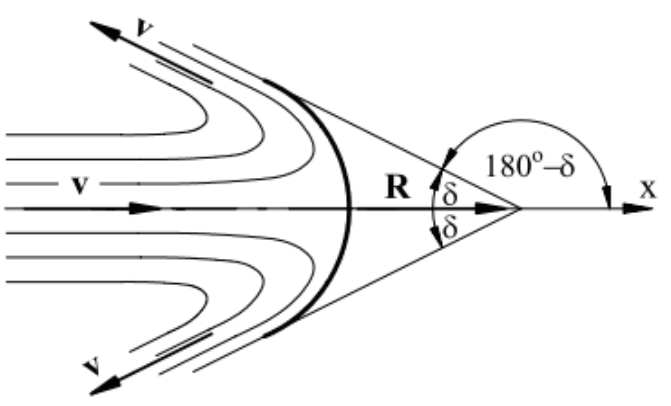

Fig. 2. Scheme of hydrodynamic thrust on the concave side of an obstacle.

The same equation is used in [15] to assess such values as rotor blade configuration, aspect ratio, overlap ratio, number of buckets to finalize the design of Savonius rotor. In contrast to the convex side of the blade facing the thrust, the correct is the relationship (2).

$$
P=A \cdot \rho \cdot v^{3} \cdot(1-\cos \delta)
$$

In order to calculate the power spectrum computing environment MatLab was used. Using the above equations (1) and (2) simulation of power that produces a single blade and the whole rotor was made. For a system comprising a rotor consisting of a given number of blades a schematic calculation algorithm is presented in Fig. 3.

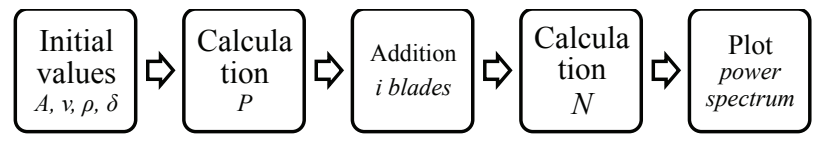

Fig. 3. Schematic representation of MatLab computing algorithm for Power Spectrum.

When determining the relationship between the size and shape of the blade and the force of thrust in order to simplify, it is assumed that the blade is fixed as in equation (1) and (2). In this case, the whole energy of moving air is absorbed by the blade. Energy formed on the blade as a whole is converted to stresses in the structure. Betz limit said that the energy of the movement of air masses can be converted to work only with $59.2 \%$ efficiency [18], which is true for horizontal axis devices and vertical airfoils [12]. However, in this case, this energy is entirely converted into a structure stress.

The determination of the previously defined values with the assumption that the blade is in motion should be done according to equations (3) when moving against the wind and (4) when moving with the wind.

$$
\begin{aligned}
& P_{Z=\rho A v^{2}(v-u)(1-\cos \delta)} \\
& P_{n=\rho A v^{2}(v+u)(1-\cos \delta)}
\end{aligned}
$$

Calculations are performed for rotors with number of $i=2$ to 7 blades and for the wind speed of $v=3$ to $14 \mathrm{~m} / \mathrm{s}$. A similar method was used for analysis of this issue in the modelling of the Savonius turbine in [14]. Later Muller et al. used it for flat plate shaped wind blade [12].
The most recent approach to VAWT related with the number of blades was made by [16] and further research to improve the drag wind turbine performance was done by [17].

For the purpose of the experiment, turbine power coefficient kmax was defined. It is the ratio of the maximum power of the turbine Nmax for the maximum power of a single blade nmax (5).

$$
k_{\max }^{i}=\frac{N_{\max }^{i}}{n_{\max }^{i}}
$$

The power turbine model expressed by a kmax coefficient depends mainly on three factors - the number of blades in a turbine $(i)$, wind speed $(v)$ and aspect ratio $(\delta)$. For the study, a constant aspect ratio adopted for the specific type of blade at the $\delta=0.9$ while wind speed and the number of blades have been edited in order to select the optimum value of the number of blades in a specific turbine.

\section{Results and discussion}

With the help of MatLab environment and the collected data the power spectrum graphs for selected cases of turbines have been prepared (Table 1).

Table 1. Power spectrum graph and $k_{\max }$ coefficient for selected rotors depending on number of blades $(v=3.0 \mathrm{~m} / \mathrm{s})$.

\begin{tabular}{|l|c|c|}
\hline $\begin{array}{c}\text { Number } \\
\text { of blades } \\
\mathrm{i}\end{array}$ & $\begin{array}{c}\text { Power spectrum } \\
\text { (for details see Fig. 4-7) }\end{array}$ & $k_{\max }$ \\
\hline 2 & & 0.92 \\
\hline 3 & & \\
\hline 5 & & 1 \\
\hline
\end{tabular}


The kmax ratio for given VAWT have been calculated. Calculations were performed for the four variants of the turbine rotor, consisted of 2, 3, 4, 5, 7 blades. Summary of cases are presented in Table. 1. The bold curve of the graphs in Table 1 represents the total power generated by the rotor. Thin coloured curves represent the power generated by a single blade. These graphs are thumbnails, full scale graphs will be presented and discussed in detail further in the paper. Presented in Table 1, the kmax ratio shows how much more power is the rotor generating compared to a single blade. The 2bladed and 3-bladed rotor generates less power than a single blade. The 4-bladed rotor generates slightly more power than a single blade, but power spectrum shows high pulsation. There is almost no pulsation for 5-bladed and 7-bladed rotor and their power is clearly higher than a single blade, but the problem appears with the thin lines in the graph. Power spectra for the single blade are getting closer to each other, which means that aerodynamic shadow and slipstream effects are getting more significant. Table 2 shows the value of kmax ratio for the 5-bladed turbine depending on the wind speed.

Table 2. Power spectrum and $k_{\max }$ coefficient for 5-bladed rotor, depending on wind velocity.

\begin{tabular}{|c|c|c|}
\hline $\begin{array}{c}\text { Wind velocity } \\
v(\mathrm{~m} / \mathrm{s})\end{array}$ & $\begin{array}{c}\text { Power Spectrum } \\
\text { (for details see Fig. 4-7 }\end{array}$ & $k_{\max }$ \\
\hline 3 & 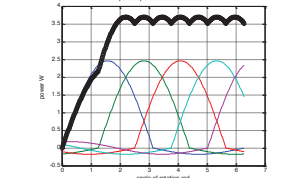 & 1.50 \\
\hline 4 & 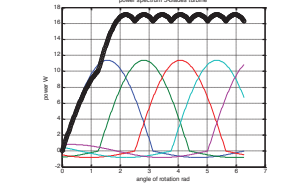 & 1.52 \\
\hline 8 & \begin{tabular}{|l|l|} 
מan \\
\\
\end{tabular} & 1.49 \\
\hline 11 & $m$ & 1.50 \\
\hline 14 & 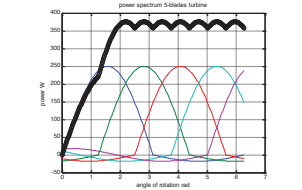 & 1.50 \\
\hline
\end{tabular}

The bold curve in Table 2 represents the total power of the rotor during the operation. Thin curves represent the power of a single blade. Again these graphs are thumbnails, full scale graphs will be presented and discussed in detail further in the paper. Presented in Table 2, the kmax ratio along with rising wind speed shows stability, thus stable operation of the rotor. As a result of experiments and calculations, based on the power spectrum plots for selected turbines, coefficient kmax can vary and in the case of this research is in the range from 0.92 to 2.12 . The results are shown in Table 3.

Table 3. The $k_{\max }$ coefficient depending on the number of blades (wind velocity $v=8.0 \mathrm{~m} / \mathrm{s}$ ).

\begin{tabular}{|c|c|c|c|c|}
\hline Number of blades $\boldsymbol{i}$ & $\mathbf{3}$ & $\mathbf{4}$ & $\mathbf{5}$ & $\mathbf{7}$ \\
\hline $\begin{array}{c}\text { Single blade power } \\
n_{\text {max }}^{i}(\mathrm{~W})\end{array}$ & 47 & 47 & 47 & 47 \\
\hline $\begin{array}{c}\text { Rotor power } N_{\max }^{i} \\
(\mathrm{~W})\end{array}$ & 44 & 62 & 70 & 100 \\
\hline$k_{\text {max }}^{i}$ & 0.93 & 1.32 & 1.49 & 2.12 \\
\hline
\end{tabular}

The following figures (Figs. 4-7) show the specific results of the calculations in the form of the power spectrum graphs with a detailed discussion.

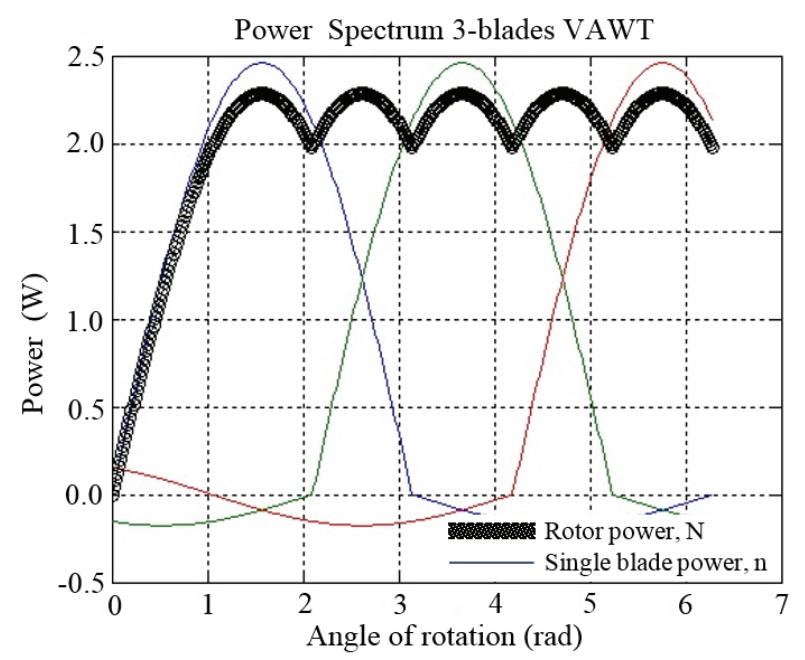

Fig. 4. The power spectrum graph for the 3-bladed VAWT.

The 3-bladed turbine, which power spectrum graph is shown in Fig. 4, produces less power than a single blade. The power coefficient kmax is less than 1 (see Table 1). This is due to the thrust equilibrium when the turbine loses power and tends to stop. Thanks to the power of inertia and the difference in the coefficient of drag, turbine has the ability to generate constant power. Although theoretic power of the 3-bladed rotor is smaller than a single blade, thus such turbine is inefficient.

The 4-bladed turbine with power spectrum graph shown in Fig. 5 produces slightly more power than a single blade. The power coefficient $k \max =1.3$ (see Table 1). However during the rotation at certain points the power of the rotor is smaller than the power of a single blade, which is still undesirable. As in the previous case, during the rotation of the rotor the torque has a high ripple - power spectrum shows high pulsation. 
The 5-bladed turbine has a power spectrum presented in Fig. 6. It produces 1.5 times more power than a single blade. The power coefficient kmax $=1.5$ (see Table 1). The power spectrum is satisfactory with little pulsation - operation of such rotor should be stable. However in this case more attention should be put on the thin lines, representing power spectra for single blades. They are getting closer to each other. This is the effect of the aerodynamic shadow.

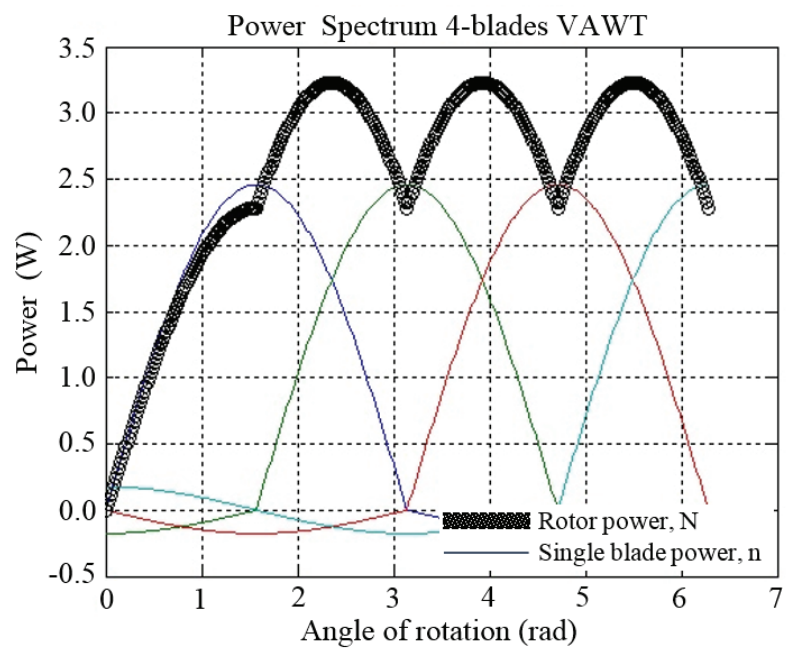

Fig. 5. The power spectrum graph for the 4-bladed VAWT.

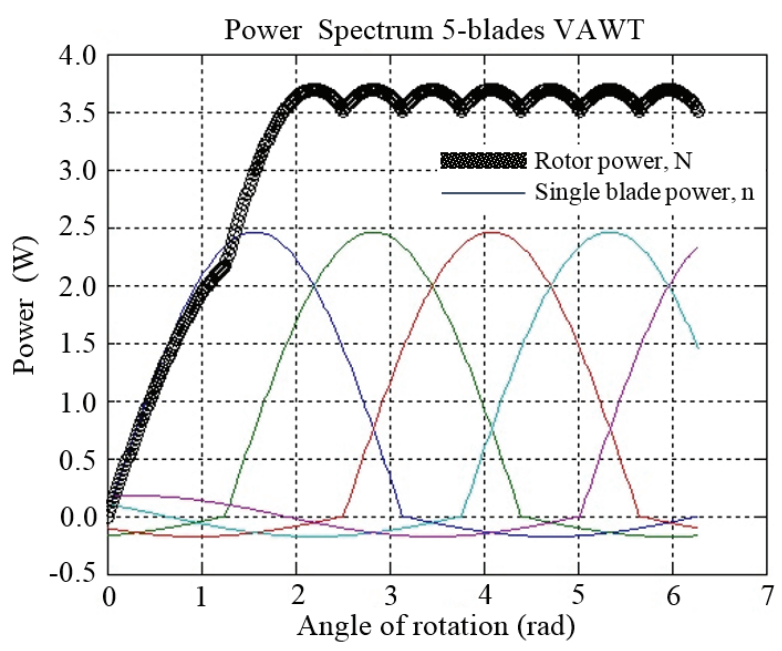

Fig. 6. The power spectrum graph for the 5-bladed VAWT.

Power spectrum graph of the 7-bladed turbine is shown in Fig. 7. This rotor has a coefficient $k \max =2.0$. The power spectrum is substantially above the power of a single blade. There is almost no pulsation, which does not cause instabilities of torque and provides a stable rotational speed of the turbine. Unfortunately it is clear that along with the increasing number of blades increases aerodynamic shadow effect.

It is efficient to apply the turbine with 5 or 7 blades. It would still follow the plot of the power spectrum of the 9-bladed turbine, but as we saw that with the 7bladed turbine the power graphs of individual blades overlap which generates slipstream stopping the rotation. This is true for relatively small turbines (up to $10 \mathrm{KW}$ ).
There is little information on how bigger rotors will operate.

Considering the application of the Betz limit one should think about how this limitation affects the movement of the VAWT blades. Does the speed of the blade may be less than the minimum air speed behind the blade, which is about $1 / 3$ of the wind speed? In the case of carousel wind turbines limitations resulting from the Betz limit are not applicable, because, as is evident from the observations: case 1) the unloaded, free rotating turbine - the blades move at the same speed as the wind and do not generate power; case 2) the fully stopped turbine - the blades do not move and all the energy goes for the generation of stresses in the structure. Between these two cases, there is a whole series of cases in which the turbine is moving at any speed less than the wind speed, and depending on the load, with less speed than resulting from Betz limit. Therefore, the wind speed behind the blades of carousel turbines does not matter because it's all about the thrust generated on the blade on both sides. Further studies are currently being conducted to help establish all these relations.

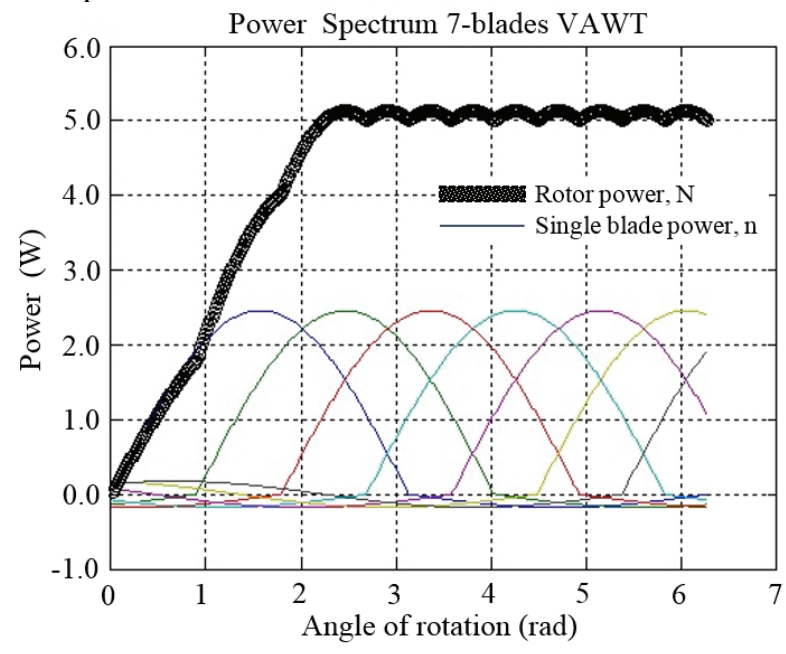

Fig. 7. The power spectrum graph for the 7-bladed VAWT.

\section{Conclusions}

The object of the study was to determine the optimum number of blades to be mounted on Vertical Axis Wind Turbine. Studies were made on the basis of thrust on the stationary blade. For this research authors resigned to examine complex phenomena occurring around the blades, i.e. aerodynamic shadow, turbulence around the blades and other aerodynamic forces. Assumed simplified (sinusoidal) change of thrust, and wind energy is completely transferred to the blade. This allowed to avoid Betz's limit [14]. These assumptions are valid for a steady state - stationary blade of the turbine set concave face perpendicular to the wind direction. Simplifications helped to determine if the parameter $k_{\max }$ can be assigned for the evaluation. As it has been shown in this study, turbine power depends on the number of blades. With the increasing number of blades mounted on the rotor, the torque also increases, and thus the rotation of turbine is smoother. Unfortunately along with the increasing number of blades, slipstream effect 
increases too. Selection of the number of blades to the turbine has a direct impact on the efficiency and economy. Too small number of blades will cause inappropriate efficiency of the turbine and therefore inadequate power. Too many blades cause, among others, the increase of the weight and the production costs.

By determining the $k_{\max }$ ratio there is possibility for a simple and rapid initial profitability characterization of bucket type wind turbines on specific weather conditions. The $k_{\max }$ ratio is specific to each single turbine and may be affected basically by wind speed variability and the number of blades. If the $k_{\max }$ ratio for the given turbine is constant over the entire range of wind velocity, that is to say that the turbine is designed properly and operates with a stable speed.

On the basis of the $k_{\max }$ ratio analysis one can select the number of blades for the turbine, which will be best fitted to the local nature of the wind. This is very important in the urban areas with high density of various buildings. Research shows that the coefficient $k_{\max }$ may take a value in the range of 0.9 to 10 . For the $k_{\max }$ ratio of 1.0 and less, does not pay to construct the turbine at all. The value of 10 is practically unattainable, because the turbine would have a huge size, which is economically viable. For small turbines with power $1-10 \mathrm{~kW}$ the $k_{\max }$ coefficient can be in the range of $1.5-3.0$. However, for $\mathrm{k}_{\max }$ greater than 2.0 one should pay particular attention to whether the slipstream effect will not reduce the power of the VAWT. Carousel drag-type VAWT are still regarded as less useful due to their low efficiency. However, due to its advantages mainly low noise, as only can be used in built-up areas. Advances in materials technology and electronics preordained that this type turbines have become interesting again. They are useful also for powering small autonomous installations where it is uneconomical to install grid. Reactive VAWT, thanks to its small size and weight have little inertia, therefore are able to capture wind energy in its gusts. Since a large proportion of wind energy is contained in the gusts, the possibility to use them is a huge advantage over the HAWT.

\section{Nomenclature}

$\begin{array}{lll}A & - & \text { surface area of the blade, } \mathrm{m}^{2} \\ N & - & \text { maximum power of the turbine, } \mathrm{W} \\ P & - & \text { thrust force, } \mathrm{kg} / \mathrm{m}^{2} \\ i & - & \text { number of blades, } \\ k & - & \text { turbine power coefficient, } \\ n & - & \text { maximum power of a single blade, } \mathrm{W} \\ u & - & \text { blade's linear velocity, } \mathrm{m} / \mathrm{s} \\ v & - & \text { wind speed, } \mathrm{m} / \mathrm{s} \\ \delta & - & \text { the blade form factor, } \\ \rho & - & \text { air density, } \mathrm{kg} / \mathrm{m}^{3}\end{array}$

\section{References}

1. T. Boczar, Wykorzystanie Energii Wiatru (WPAK, Gliwice, 2010)
2. W.T. Chong, A. Fazlizan, S.C. Poh, K.C. Pan, W.P. Hew, F.B. Hsiao, Appl. Energy 112, 601-609 (2013)

3. H. Lu, P. Zeng, L. Lei, Y. Yang, Y. Xu, L. Qian, 88, pp 535-544 (2014)

4. N. Duić, M. Ban, L. Perković, P. Silva, N. Kranjčević, Appl. Energy 101, 151-160 (2013)

5. M. Islam, D.S.K. Ting, A. Fartaj, Renewable Sust. Energy Rev. 12, 1087-1109 (2008)

6. S. Bhuyan, A. Biswas, Energy Convers. Manage. 87, 859-867 (2014)

7. E. Kabalci, Energy Convers. Manage. 72, 51-59 (2013)

8. M. Wzorek, M. Tańczuk, Waste Manage. Res. 33, 8 704-714 (2015)

9. J.D. Bishop, G.A. Amaratunga, Energ Convers. Manage. 49, 6, 1652-1661 (2008)

10. A.D. Peacock, D. Jenkins, M. Ahadzi, A. Berry, S. Turan, Energ. Buildings 40, 7, 1324-1333 (2008)

11. Q. Li, T. Maeda, Y. Kamada, J. Murata, K. Furukawa, M. Yamamoto, Energy 90, 784-795 (2015)

12. G. Muller, M.F. Jentsch, E. Stoddart, Renewable Energy 34, 1407-1412 (2009)

13. K. Jeżowiecka-Kabsch, H. Szewczyk, Mechanika Plynów (OWPW, Wrocław, 2001)

14. J.-L. Menet, Renewable Energy 29, 1843-1862 (2004)

15. I. Al-Bahadly, Energy Sustainable Develop. 13, 3, 159-165 (2009)

16. F. Wenehenubun, A. Saputra, H. Sutanto, Energy Procedia 68, 297-304 (2015)

17. A. R. El-Baz, K. Youssef, M. H. Mohamed, Renewable Energy 86, 89-98 (2016)

18. O. Ozgener, Energ. Convers. Manage. 47, 1326-1337 (2006) 